\title{
Using CATME to Document and Improve the Effectiveness of Teamwork in Capstone Courses
}

\author{
Mr. Behzad Beigpourian, Purdue University, West Lafayette
}

Behzad Beigpourian is a Ph.D. student and Research Assistant in Engineering Education at Purdue University. He earned his master's in Structural Engineering from Shahid Chamran University in Iran, and his bachelor's in Civil Technical Teacher from Shahid Rajaee Teacher Training University in Iran, Tehran. He has been official Technical Teacher at Ministry of Education in Iran from 2007 to 2018, and received many certificate in education such as Educational Planning, Developing Research Report, and Understanding School Culture. During these years, he has taught construction courses in several technical schools. Mr. Beigpourian currently works in the CATME project, which is NSF funding project, on optimizing teamwork skills and assessing the quality of Peer Evaluations.

\section{Dr. Daniel M. Ferguson, Purdue University, West Lafayette}

Daniel M. Ferguson is CATME Managing Director and the recipient of several NSF awards for research in engineering education and a research associate at Purdue University. Prior to coming to Purdue he was Assistant Professor of Entrepreneurship at Ohio Northern University. Before assuming that position he was Associate Director of the Inter-Professional Studies Program [IPRO] and Senior Lecturer at Illinois Institute of Technology and involved in research in service learning, assessment processes and interventions aimed at improving learning objective attainment. Prior to his University assignments he was the Founder and CEO of The EDI Group, Ltd. and The EDI Group Canada, Ltd, independent professional services companies specializing in B2B electronic commerce and electronic data interchange. The EDI Group companies conducted syndicated market research, offered educational seminars and conferences and published The Journal of Electronic Commerce. He was also a Vice President at the First National Bank of Chicago [now J.P. Morgan Chase], where he founded and managed the bank's market leading professional Cash Management Consulting Group, initiated the bank's non-credit service product management organization and profit center profitability programs and was instrumental in the breakthrough EDI/EFT payment system implemented by General Motors. Dr. Ferguson is a graduate of Notre Dame, Stanford and Purdue Universities, a special edition editor of the Journal of Engineering Entrepreneurship and a member of Tau Beta Pi.

\section{Dr. Frederick C. Berry, Purdue Polytechnic Institute}

Frederick C. Berry received the B.S.E.E., M.S.E.E. and D.Engr. degrees from Louisiana Tech University in 1981, 1983, and 1988 respectfully. Dr. Berry is Professor in the School of Engineering Technology at Purdue University. Recent research has focused on 1) using writing and communication assignments to improve the teaching of engineering design and 2) developing a flexible mobile studio pedagogy using the Mobile Studio Instrumentation Board.

\section{Dr. Matthew W. Ohland, Purdue University, West Lafayette}

Matthew W. Ohland is Professor of Engineering Education at Purdue University. He has degrees from Swarthmore College, Rensselaer Polytechnic Institute, and the University of Florida. His research on the longitudinal study of engineering students, team assignment, peer evaluation, and active and collaborative teaching methods has been supported by the National Science Foundation and the Sloan Foundation and his team received Best Paper awards from the Journal of Engineering Education in 2008 and 2011 and from the IEEE Transactions on Education in 2011 and 2015. Dr. Ohland is an ABET Program Evaluator for ASEE. He was the 2002-2006 President of Tau Beta Pi and is a Fellow of the ASEE, IEEE, and AAAS.

\section{Mr. Siqing Wei, Purdue University, West Lafayette}

Siqing Wei received bachelor degree in Electrical and Computer Engineering at Purdue University. He is in the dual program to obtain master degree in Electrical and Computer Engineering and Ph.D degree 
in Engineering Education at Purdue University. After years of experience of serving a peer teacher and a graduate teaching assistant in first year engineering courses, he is now interested in study of the existence, cause and interventions on international engineers' teaming behaviors. 


\title{
Using CATME to Document and Improve the
}

\section{Effectiveness of Teamwork in Capstone Courses}

\begin{abstract}
This paper examines the use of peer evaluations and associated personal and team questions to diagnosis team functionality and provide early diagnosis of team dysfunctionalities.

For a large STEM Capstone program in a major Midwestern university we collected peer evaluation data three times and examined both peer evaluation data and the relationships to the peer ratings of additional questions on teammates perception of psychological safety, team conflict, team cohesiveness, personal satisfaction with their team experience, and their written peer to peer comments explaining their peer ratings.

We used the CATME peer evaluation system to collect the peer ratings and the additional questions data. CATME is a tool for forming and managing teams that has been used by over one million students to date. CATME's peer evaluation tool has five behaviorally anchored dimensions and additional team process measures that can be collected along with the peer evaluation data.

We found strong correlations among team cohesiveness, team conflict and psychological safety questions. In addition, we developed heuristics by which problematic teams can be identified based on examining several of these team process scores simultaneously. In particular, psychological safety questions are strongly correlated negatively with team conflict feedback and positively correlated with team cohesion question feedback. These problem team indicators were strongly confirmed by the faculty mentoring our sample teams. A second useful team problem indicator was a lack of participation in the peer evaluation process. A final indicator of problematic teams was one or more low absolute levels of peer ratings for an individual team member and the nature of written peer to peer comments explaining the students' self and teammate peer ratings.
\end{abstract}

\section{Keywords}

CAPSTONE teams, CATME, Peer evaluation, psychological safety, conflict, cohesiveness, satisfaction

\section{Introduction}

Like many disciplines, engineering programs use teams in some courses because the engineering curriculum prepares students to work on multidisciplinary teams [1]. Engineering students usually take a capstone course in the last year of their studies. In capstone courses, instructors simulate real-world problems, often with assistance of external sponsors [2], match student teams with projects [2], [3], identify team leaders to increase team effectiveness, assess teams during the projects, diagnose team dysfunctions, and help students learn to improve their work in teams [2]. Instructors also aim to develop the students' professional skills for communication and interpersonal dynamics [4]. These multiple goals and the associated project challenges make teaching a Capstone course a difficult instructor assignment. 
CATME is a web-based tool that has been used by over one million students. CATME includes tools for peer evaluation, team formation, and assessing teamwork skills [5]-[9]. Also, many researchers, in many disciplines and countries have used CATME to investigate teamwork learning.; Lau, Kwong, Chong, and Wong [10] used CATME in Hong Kong to find how teamwork skills developed among freshmen students. CATME was used to measure the individuals' teamwork performance in pharmacy courses [11]. Godwin, Kirn, and Rohde [12] used CATME in freshmen engineering to measure learning of teamwork skills in diverse teams. In this study, we used CATME as peer evaluation tool. Students rate themselves and their teammates in five different behaviorally ranked teamwork dimensions. In addition, team outcome measures including psychological safety, personal satisfaction, team conflict, and team cohesiveness can be used to better measure teamwork interactions.

Assessing student's teamwork skills during a project potentially helps students improve those skills. Peer evaluation in the middle of the project also helps students to improve their team's performance [13]. Many researchers who have investigated the use of peer evaluations in engineering course [14]-[17] concluded that peer and self-evaluations increase student's teamwork skills [18] and motivate students to collaborate for the same teamwork goal [19]. CATME's peer evaluation framework includes five validated teamwork behavior dimensions: Contributing to the team's work, Interacting with teammates, Keeping the team on the track, Expecting quality, and Having relevant knowledge, skills, and abilities (KSAs). CATME also provides Rater Practice tools and Frame-of-Reference training to improve the quality of peer evaluation [8]. We also examined each individual and team on four additional evaluations of team performance or personal evaluation of the team. These four additional evaluations covered a student's perception of team: Conflict, Cohesiveness, Satisfaction, and Psychological Safety:

\section{Conflict}

Organizational psychological scholars have investigated interpersonal conflict for decades [20]. Conflict in teams can be due to different levels of commitment, dissimilar ideas for directing the project, and various working styles [21]. However, conflict can be defined with a different view and can be both positive and negative for teams depending on different factors [22]. For example, task conflict can increase the quality of ideas [23]. Depending on the type of conflicts, sometimes they should be only managed and sometimes immediately resolved [23]. So, in both situations, instructors should be aware of conflict in Capstone teams.

\section{Cohesiveness}

Cohesiveness is a bond between members of a team that can increase the productivity of teams [24]. Teams with higher cohesiveness have higher performance [25]. There is substantial research on team cohesiveness in sport, psychology, and management journals, and they agree that increasing team cohesion by implementing effective interventions can enhance team performances [26]. 


\section{Satisfaction}

Satisfaction of team members with their team and project can be due to satisfaction with other team members, the composition of the team, or the quality of collaboration. If team members are satisfied with their teams, they are willing to continue working with those teams in the future [27].

\section{Psychological Safety}

Psychological safety is the team member's belief about being safe to take interpersonal risks in teams [28]. For learning more and contributing better, people need to feel safe at work [29]. When people are working with people who are assessing them, people try to keep their image good in the mind of their teammates and minimize their risk [30].

\section{Method}

\section{Data collection}

We collected our data from a STEM Capstone course in a large Midwestern public university. 154 students in teams with three, four, five, and six students conducted self and peer evaluations at three different stages through the semester. We had. In each peer evaluation, they also answered psychological safety, conflict, cohesiveness, and satisfaction questions.

\section{Peer evaluation}

In each peer evaluation, students rated all team members including themselves in five behaviorally ranked dimensions; contributing to the team's work, interacting with teammates, keeping the team on track, expecting quality, and having relevant KSAs.

\section{Conflict}

There are three different types of conflict; task conflict, relationship conflict, and process conflict [31]. For each type of conflict, students answered three questions on a five-point scale. Then, we used the mean of all nine questions as the value of conflict for a student. Five means the highest conflict and one means the lowest conflict. For conflict we used these nine questions by Jehn and Mannix [32]: "How much conflict of ideas is there in your work group?", "How frequently do you have disagreements within your work group about the task of the project you are working on?", and "How often do people in your work group have conflicting opinions about the project you are working on?" for task conflict, "How much relationship tension is there in your work group?", "How often do people get angry while working in your group?", and "How much emotional conflict is there in your work group?" for relationship conflict, and "How often are there disagreements about who should do what in your work group?", "How much conflict is there in your group about task responsibilities?", and "How often do you disagree about resource allocation in your work group?" for process conflict. 


\section{Cohesiveness}

For the students' perception of team cohesiveness, we used nine questions by Carless and de Paola [33], [34]: "Being part of the team allows team members to do enjoyable work", "Team members get to participate in enjoyable activities" "Team members like the work that the group does", "Team members like each other", " Team members get along well”, "Team members enjoy spending time together", "Our team is united in trying to reach its goals for performance" , "I'm unhappy with my team's level of commitment to the task." (Reversed), and "Our team members have conflicting aspirations for the team's performance" (reversed).

Some questions are reversed scaled which means if a student strongly agrees with the question, a student has the lowest cohesion. We used the adjusted mean for all these nine questions as the cohesiveness value for a student. Adjusted mean calculated by considering the reversed scale questions. Five is the highest cohesion and one is the lowest cohesion.

\section{Satisfaction}

For all three peer evaluations, we collected personal satisfaction data by asking students to answer these three questions by Van der Vegt, Emans, and Van de Vliert [35]: "I am satisfied with my present teammates", "I am pleased with the way my teammates and I work together", and "I am very satisfied with working in this team". We used the adjusted mean as a satisfaction value for a student. Five is equal to highest satisfaction and one is equal to lowest satisfaction.

\section{Psychological Safety}

Psychological safety data was collected using psychological safety questions by Edmondson [28]: "If you make a mistake on this team, it is often held against you. (reversed scale)", "Members of this team are able to bring up problems and tough issues", "People on this team sometimes reject others for being different. (reversed scale)", "It is safe to take a risk on this team, it is difficult to ask other members of this team for help. (reversed scale)", "No one on this team would deliberately act in a way that undermines my efforts.", and "Working with members of this team, my unique skills and talents are valued and utilized." We used a sevenpoint scale and some questions are reversed. Seven means highest psychological safety and one means lowest psychological safety.

\section{Results}

\section{Quality of peer evaluation}

A key analysis in this study uses the Social Relations Model (SRM). The SRM evaluates three key variances in teamwork peer rating data: rater, target, and relationship variance. Rater Variance describes how a team member rates their teammates. A larger rater variance would indicate that a team member is giving their teammates similar ratings, a weaker peer 
rating as there is less differentiation across CATME dimensions or teammates. Target Variance measures how consistently an individual is rated by their teammates. A larger target variance would indicate that a student is being rated consistently by teammates. Relationship Variance measures how uniquely an individual is rating their teammates, and particularly their behavior toward that specific team member. A larger relationship variance would indicate that an individual is rating their teammates based on reasons outside of the team context [36]-[38]. We examine only Rater and Target Variance in this analysis of Capstone teams.

Figure 1 shows that for all students from all teams in this Capstone course they record relatively high Rater Variance data in all three peer ratings, and especially in the $1^{\text {st }}$ and $3^{\text {rd }}$ peer ratings and relatively low target variance data across all three peer ratings. High Rater Variance implies that the students in many teams did not take the peer rating seriously or for other reasons did not constructively provide feedback to their teammates [e.g., If everyone on the team was rated as behaving exactly the same way all the time there is no useful peer rating data-e.g., all clones?] The reasons for the changes in Rater Variance and Target Variance from rating 1 to rating 2 and rating 2 to rating 3 are not known.

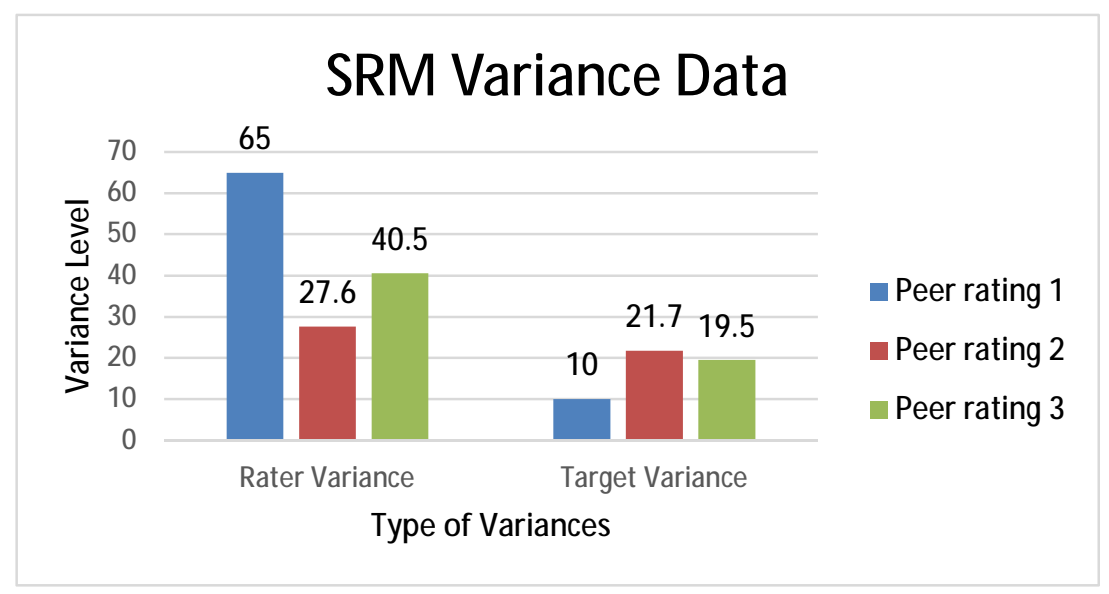

Figure 1. Overall SRM results peer ratings 1-3

\section{Examining average changes in cohesiveness, conflict, satisfaction, and psychological safety in teams across multiple peer ratings.}

Investigating the changes in cohesiveness and conflict in the sample teams during the semester, we conducted a paired samples t-test. There was not a significant difference in the cohesiveness of teams in from peer rating $2(\mathrm{M}=3.96, \mathrm{SD}=0.5)$ and cohesiveness of teams in peer rating $3(\mathrm{M}=4.01, \mathrm{SD}=0.39), \mathrm{t}(26)=-0.68, \mathrm{p}=0.5$. The mean conflict rating in teams slightly decreased in peer rating 3 , but there was not a significant difference in the conflict of teams from peer rating $2(\mathrm{M}=1.62, \mathrm{SD}=0.4)$ and conflict of teams in peer rating $3(\mathrm{M}=1.6$, $\mathrm{SD}=0.33), \mathrm{t}(26)=0.22, \mathrm{p}=0.83$. 
In addition, we conducted a one-way repeated measure ANOVA to compare the change sin psychological safety and satisfaction in peer ratings 1,2 , and 3 . Although teams had the highest psychological safety mean rating in peer rating 3, there was not a significant change in perception of psychological safety, Wilks' Lambda $=0.97, \mathrm{~F}(2,25)=0.355, \mathrm{p}=0.7$ Also, there was a significant decrease of satisfaction, Wilks' Lambda $=0.78, \mathrm{~F}(2,25)=0.355$, $\mathrm{p}=0.048$. We used pairwise for the post hoc. A pairwise test indicated satisfaction that there was a significant between in decrease from peer rating $1((\mathrm{M}=4.33, \mathrm{SD}=0.34)$ to peer rating 3 $(\mathrm{M}=4.14, \mathrm{SD}=0.57)$.

\section{Comparing team levels of conflict, cohesion and psychological safety}

By comparing the question data for each team, we identified those teams for which the peer evaluations or additional questions information pointed to potential trouble spots/teams.

Table 1 Data for the peer Ratings and Questions Asked in Conjunction with Peer Rating 1.

\begin{tabular}{|c|c|c|c|c|c|c|c|}
\hline $\begin{array}{l}\text { PROBLEM } \\
\text { TEAMS }\end{array}$ & $\begin{array}{c}\text { Number of } \\
\text { team } \\
\text { Members }\end{array}$ & $\begin{array}{c}\text { Rater } \\
\text { Variance } \\
>70 \% \\
\end{array}$ & $\begin{array}{c}\text { Target } \\
\text { Variance }\end{array}$ & $\begin{array}{l}\text { Psychologi } \\
\text { cal Safety } \\
=<4.7\end{array}$ & \begin{tabular}{|c|} 
Satisfica \\
tion $<$ \\
4.0 \\
\end{tabular} & $\begin{array}{c}\text { Conflict } \\
>1.6 \\
\end{array}$ & $\begin{array}{c}\text { Cohesive } \\
\text { ness }< \\
4.0 \\
\end{array}$ \\
\hline 1 & 5 & 30.8 & 30.8 & 4.71 & \begin{tabular}{|l|}
4.47 \\
\end{tabular} & & 4.09 \\
\hline 2 & 3 & No SRM & No SRM & 5.19 & 4.44 & & 4.63 \\
\hline 3 & 6 & 0 & 0 & 4.76 & 4.11 & & 3.91 \\
\hline 4 & 4 & 71.4 & 14.3 & 5.18 & 4.25 & & 4.28 \\
\hline 5 & 3 & No SRM & No SRM & 5 & 3.78 & & 3.63 \\
\hline 6 & 6 & 75 & 0 & 5 & 4.72 & & 4.39 \\
\hline 7 & 4 & 75 & 0 & 5.18 & 4.42 & & 4.44 \\
\hline 8 & 3 & No SRM & No SRM & 5.24 & 4.67 & & 4.44 \\
\hline 9 & 4 & 0 & 0 & 5.29 & 4.42 & & 4.39 \\
\hline 10 & 5 & 100 & 0 & 4.71 & 4.13 & & 4.09 \\
\hline 11 & 4 & 44.4 & 0 & 5.18 & 4.75 & & 4.36 \\
\hline 12 & 4 & 83.3 & 0 & 5.18 & 4.33 & & 4.03 \\
\hline 13 & 4 & 72.7 & 9.1 & 5.07 & 4.58 & & 4.33 \\
\hline 14 & 3 & No SRM & No SRM & 5.38 & 4.56 & & 4.33 \\
\hline 15 & 3 & No SRM & No SRM & 5.24 & 4.78 & 1.41 & \\
\hline 16 & 6 & No SRM & No SRM & 4.86 & 4.44 & 1.15 & \\
\hline 17 & 3 & No SRM & No SRM & 5.43 & 4.44 & 1.67 & \\
\hline 18 & 3 & No SRM & No SRM & 5 & 4.56 & 1.26 & \\
\hline 19 & 3 & No SRM & No SRM & 5.1 & 4.56 & 1.37 & \\
\hline 20 & 4 & 0 & 0 & 4.75 & 4.17 & 1.61 & \\
\hline 21 & 5 & 0 & 0 & 4.91 & 3.53 & 1.27 & \\
\hline 22 & 6 & 57 & 19.8 & 4.83 & 4.06 & 1.61 & \\
\hline 23 & 3 & No SRM & No SRM & 4.48 & 4.33 & 1.48 & \\
\hline 24 & 5 & 76.9 & 0 & 5.37 & 4.6 & 1.2 & \\
\hline 25 & 6 & 0 & 0 & 4.48 & 4.17 & 1.28 & \\
\hline 26 & 6 & 55 & 10 & 4.36 & 3.5 & 1.69 & \\
\hline 27 & 5 & 82.4 & 0 & 4.46 & 4.07 & 1.6 & \\
\hline mean & 4.30 & & & 4.98 & 4.33 & 1.43 & 4.24 \\
\hline std dev & & & & 0.30 & 0.34 & 0.19 & 0.26 \\
\hline
\end{tabular}

*Colored cells are team scores more than one standard deviation for the mean score. 
Table 1 Notes:

1. If any team has two or more colored boxes there is an indication of a team problem in their work as a team or in their use of peer ratings.

2. The problem trip wires for team cohesiveness, satisfaction, team conflict and psychological safety were set roughly at 1 standard deviation away from the mean score.

3. Teams 3, 5, 10, 20, 21, 26 and 27 were identified as potential problem teams and those findings were confirmed by the Capstone faculty.

4. NO SRM means that data for use of the SRM model was not complete.

We also found as shown in table 2 that Psychological Safety and satisfaction were strongly correlated with both cohesion [positively] and conflict [negatively]. These correlations hold throughout the three peer ratings and the question correlations for peer rating 2 are shown in Table 3.

Table 2 Correlation of the team questions in Peer Rating 1

\begin{tabular}{lcccc}
\hline & Psychological Safety & Satisfaction & Conflict & Cohesiveness \\
\hline Psychological Safety & 1 & & & \\
Satisfaction & 0.58 & 1 & & \\
Conflict & -0.27 & -0.35 & 1 & \\
Cohesiveness & 0.55 & 0.78 & - & 1 \\
\hline
\end{tabular}

Table 3 Correlation of the team questions in Peer Rating 2

\begin{tabular}{lrrrr}
\hline & Psychological Safety & Satisfaction & Conflict & Cohesiveness \\
\hline Psychological Safety & 1 & & & \\
Satisfaction & 0.84 & 1 & & \\
Conflict & -0.84 & -0.8 & 1 & \\
Cohesiveness & 0.80 & 0.92 & -0.84 & 1 \\
\hline
\end{tabular}

In Table 4 we see the results of the $2^{\text {nd }}$ peer rating and the analysis of the team peer ratings and other questions. The same set of teams identified in the first peer rating [Teams 3,5, 10, 20,21, 26 and 27] are still indicating team problems and 2 more teams indicate problem behaviors [teams 6 and 25]. 
Table 4 Data for the peer Ratings and Questions Asked in Conjunction with Peer Rating 2.

\begin{tabular}{|c|c|c|c|c|c|c|c|c|}
\hline $\begin{array}{c}\text { 1st } \\
\text { Peer } \\
\text { Rating } \\
\text { PRO } \\
\text { BLEM } \\
\text { TEAMS } \\
\end{array}$ & $\begin{array}{l}\text { Num } \\
\text { ber of } \\
\text { team } \\
\text { Mem } \\
\text { bers }\end{array}$ & $\begin{array}{c}\text { SRM } \\
\text { Model } \\
\text { Rater } \\
\text { Varianc } \\
\text { e }>70 \%\end{array}$ & $\begin{array}{c}\text { SRM } \\
\text { Model } \\
\text { Target } \\
\text { Varianc } \\
\text { e }\end{array}$ & $\begin{array}{c}\text { Psychologica } \\
\text { I Safety =< } \\
4.7\end{array}$ & $\begin{array}{c}\text { Satisfac } \\
\text { tion }<4.0\end{array}$ & $\begin{array}{c}\text { Conflict }> \\
1.6\end{array}$ & $\begin{array}{l}\text { Cohesiven } \\
\text { ess }<4.0\end{array}$ & $\begin{array}{l}\text { 2nd } \\
\text { Peer } \\
\text { Rating } \\
\text { PRO } \\
\text { BLEM } \\
\text { TEAM } \\
\mathrm{S}\end{array}$ \\
\hline 1 & 5 & 10 & 30 & 5 & 4.4 & 1.4 & 4.18 & \\
\hline 2 & 3 & No SRM & No SRM & 5.62 & 4.56 & 1.26 & 4.37 & \\
\hline 3 & 6 & 90 & 0 & 4.81 & 4.22 & 1.74 & 3.89 & 3 \\
\hline 4 & 4 & 0 & 0 & 5.32 & 4.67 & 1.56 & 3.97 & \\
\hline 5 & 3 & No SRM & No SRM & 4 & 3.11 & 2.44 & 2.85 & 5 \\
\hline 6 & 6 & 71.3 & 7.4 & 5.31 & 4.06 & 1.31 & 3.89 & 6 \\
\hline 7 & 4 & 67 & 0 & 5.14 & 4.25 & 1.22 & 4.5 & \\
\hline 8 & 3 & No SRM & No SRM & 5.43 & 4.33 & 1.22 & 4.19 & \\
\hline 9 & 4 & 50 & 0 & 5.43 & 4.58 & 1.33 & 4.5 & \\
\hline 10 & 5 & 0 & 35 & 4.54 & 3.87 & 1.84 & 3.71 & 10 \\
\hline 11 & 4 & 67 & 0 & 5.64 & 4.75 & 1.42 & 4.53 & \\
\hline 12 & 4 & 80 & 0 & 5.29 & 4.75 & 1.56 & 4.06 & \\
\hline 13 & 4 & 28.6 & 0 & 5.36 & 4.75 & 1.75 & 4.42 & \\
\hline 14 & 3 & No SRM & No SRM & 5 & 4.56 & 1.56 & 4.15 & \\
\hline 15 & 3 & No SRM & No SRM & 5.05 & 4.67 & 1.56 & 4 & \\
\hline 16 & 6 & 0 & 0 & 5.07 & 4.33 & 1.26 & 4.3 & \\
\hline 17 & 3 & No SRM & No SRM & 5.5 & 5 & 1.22 & 4.83 & \\
\hline 18 & 3 & No SRM & No SRM & 5.05 & 3.67 & 1.52 & 3.7 & 18 \\
\hline 19 & 3 & No SRM & No SRM & 5.14 & 4.33 & 1.78 & 4.04 & \\
\hline 20 & 3 & No SRM & No SRM & 5.05 & 3.67 & 1.63 & 3.44 & 20 \\
\hline 21 & 5 & 0 & 0 & 4.91 & 3.93 & 1.38 & 3.76 & 21 \\
\hline 22 & 6 & 26.8 & 54.9 & 4.19 & 4.28 & 1.57 & 3.94 & \\
\hline 23 & 3 & No SRM & No SRM & 4.95 & 4.11 & 1.93 & 3.93 & \\
\hline 24 & 5 & 77 & 0 & 4.71 & 4.6 & 1.27 & 4.44 & \\
\hline 25 & 6 & 29.8 & 23.4 & 4.21 & 2.94 & 2.13 & 3.09 & 25 \\
\hline 26 & 6 & 1 & 95 & 2.88 & 2.28 & 2.94 & 2.76 & 26 \\
\hline 27 & 5 & 0 & 39 & 4.03 & 3.53 & 2 & 3.53 & 27 \\
\hline Mean & & & & 4.9 & 4.2 & 1.6 & 4.0 & \\
\hline Stdev & & & & 0.6 & 0.6 & 0.4 & 0.5 & \\
\hline
\end{tabular}

\section{Peer to peer comments and teams' outcome}

We exposed more of the issues in the teams by looking at the comments provided by students in the high conflict teams. For example, Team 3 with six members experienced low conflict in the first peer rating as a student in team 3 commented:

"The team works well together. I am pleased." 
But, conflict increased in this team in peer rating 2 so that the student in team 3 commented:

"The team is really struggling with personnel issues. I don't know what motivates these guys and cannot seem to get the ball rolling. I am not sure if it's the scope, or just a couple lazy people. We cannot finish this project with only 4 working people, so I hope to motivate and keep hold the people accountable for GOOD work."

And a student in this same team commented:

"We are currently having issues with two members of our group not contributing the scores given in the CATME show which members these are. They either show up very late to the meetings or not at all. The quality of work is not very high either. For the size of the project, we really need all members working to their fullest potential and unfortunately student 2 and student 4 are more a liability than an asset to the team."

\section{Discussion}

Most Teams experienced high cohesiveness, psychological safety, and satisfaction and low conflict in all three peer ratings which shows that most teams were working effectively on their projects. While these road signs do not guarantee project outcome success, it is more likely with more smoothly functioning project teams. Some teamwork problems emerged in successive peer ratings [teams 6 and 25] that were not evident initial peer ratings as the semester project worked progressed. Initial problems also became more serious as the semester moved forward but were better illuminated by the written peer to peer comments.

The high correlations between the variables (conflict, cohesiveness, psychological safety, and satisfaction) testified that students did not answer the questions randomly. For instance, conflict had a very strong and continuing negative correlation with other variables. Starting in peer rating three we collected peer to peer written comments and these comments provided new insights into the team member behaviors that were causing the high conflict and related negative interaction [safety, satisfaction] scores. Our findings on potential problem teams were confirmed by the team mentors and faculty supervisors. This confirmation was critical in reinforcing the design of our team problem analysis heuristics.

\section{Conclusions}

Combining the insights derived across the multiple types of questions and the multiple peer ratings into the picture of team performance to date as illustrated in Tables 1 and 4 identifies potential problem capstone teams.

Use of our peer rating data collection strategy and analysis heuristics potentially offers instructors using teams, particularly in Capstone courses, a way to focus more of their limited time and energy on teams with problems that can potentially be addressed within the academic term This can produce benefits for both the students' teamwork learning and for the quality of the [sponsored] project results. 


\section{Limitation and future studies}

In this study, we investigated one capstone class, and for one semester. We are going to continue this study for another semester. This study also included teams of different sizes. We do not know if team size has an impact on Capstone team performance, but research says it will if not all the necessary project resources are available to team members. We will be adding outcome data, project grades, to our analysis so that we can determine if our model insights will serve as predictive model.

\section{References}

[1] ABET, 2018-19 Criteria for Accrediting Engineering Programs. Baltimore, MD: ABET, 2019.

[2] M. W. Ohland, D. Giurintano, B. Novoselich, P. Brackin, and S. Sangelkar, "Supporting capstone teams: Lessons from research on motivation," Int. J. Eng. Educ., vol. 31, no. 6, pp. 1748-1759, 2015.

[3] M. Steiner and J. Kanai, "Creating effective multidisciplinary capstone project teams," Int. J. Eng. Educ., vol. 32, no. 2, pp. 625-639, 2016.

[4] M. Paretti, R. Layton, S. Laguette, and G. Speegle, "Managing and mentoring capstone design teams: Considerations and practices for faculty," Int. J. Eng. Educ., vol. 27, no. 6, pp. 1192-1205, 2011.

[5] M. L. Loughry, M. W. Ohland, and D. J. Woehr, "Assessing teamwork skills for assurance of learning using CATME team tools," J. Mark. Educ., vol. 36, no. 1, pp. 519, Apr. 2014.

[6] M. W. Ohland et al., "The comprehensive assessment of team member effectiveness: Development of a behaviorally anchored rating scale for self- and peer evaluation," Acad. Manag. Learn. Educ., vol. 11, no. 4, pp. 609-630, Dec. 2012.

[7] R. A. Layton, M. L. Loughry, M. W. Ohland, and G. D. Ricco, "Design and validation of a web-based system for assigning members to teams using instructor-specified criteria," Adv. Eng. Educ., vol. 2, no. 1, pp. 1-28, 2010.

[8] A. C. Loignon, D. J. Woehr, J. S. Thomas, M. L. Loughry, M. W. Ohland, and D. M. Ferguson, "Facilitating peer evaluation in team contexts: The impact of frame-ofreference rater training," Acad. Manag. Learn. Educ., vol. 16, no. 4, pp. 562-578, 2017.

[9] M. L. Loughry, M. W. Ohland, and D. DeWayne Moore, "Development of a theorybased assessment of team member effectiveness," Educ. Psychol. Meas., vol. 67, no. 3, pp. 505-524, Jun. 2007.

[10] P. Lau, T. Kwong, K. Chong, and E. Wong, "Developing students' teamwork skills in a cooperative learning project," Int. J. Lesson Learn. Stud., vol. 3, no. 1, pp. 80-99, 2013.

[11] L. D. Camiel, M. Kostka-Rokosz, G. Tataronis, and J. Goldman, "Performance and perceptions of student teams created and stratified based on academic abilities," Am. J. 
Pharm. Educ., vol. 81, no. 3, p. 47, 2017.

[12] A. Godwin, A. Kirn, and J. Rohde, "Awareness without action: Student attitudes after engineering teaming experiences," Int. J. Eng. Educ., vol. 33, no. 6a, pp. 1878-1891, 2017.

[13] A. Agogino, S. Song, and J. Hey, "Triangulation of indicators of successful student design teams," Int. J. Eng., vol. 22, no. 3, pp. 617-625, 2006.

[14] S. Nikolic, D. Stirling, and M. Ros, "Formative assessment to develop oral communication competency using YouTube: self- and peer assessment in engineering,” Eur. J. Eng. Educ., vol. 43, no. 4, pp. 538-551, 2018.

[15] S. Vasana and A. D. Ritzhaupt, "A case study of a method for hybrid peer-evaluation in engineering education," World Trans. Eng. Technol. Educ., vol. 7, no. 1, pp. 34-40, 2009.

[16] B. C. Williams, B. B. He, D. F. Elger, and B. E. Schumacher, "Peer Evaluation as a motivator for improved team performance in Bio/Ag Engineering design classes.," Int. J. Eng. Educ., vol. 23, no. 4, pp. 698-704, 2007.

[17] L. M. O'moore and T. E. Baldock, "Peer assessment learning sessions (PALS): An innovative feedback technique for large engineering classes," Eur. J. Eng. Educ., vol. 32, no. 1, pp. 43-55, 2007.

[18] G. Thomas, D. Martin, and K. Pleasants, "Using self- and peer-assessment to enhance students ' future-learning in higher education .," J. Univ. Teach. Learn. Pract., vol. 8, no. 1, pp. 1-17, 2011.

[19] B. J. Millis and J. Philip G. Cottell, Cooperative learning for higher education faculty. Phoenix, Ariz: Oryx Press, 1998.

[20] F. Chiocchio, D. Forgues, D. Paradis, and I. Iordanova, "Teamwork in integrated design projects: Understanding the effects of trust, conflict, and collaboration on performance," Proj. Manag. J., vol. 42, no. 6, pp. 78-91, 2011.

[21] X. Neumeyer and A. McKenna, "Conflict behavior and its influence on engineering design teams," in ASEE Annual Conference and Exposition, Conference Proceedings, 2010 .

[22] K. A. Jehn and C. Bendersky, "Intragroup conflict in organizations: A contingency perspective on the conflict-outcome relationship," Research in Organizational Behavior. 2003.

[23] J. S. Karn and A. J. Cowling, "Measuring the effect of conflict on software engineering teams," Behav. Res. Methods, vol. 40, no. 2, pp. 582-589, 2008.

[24] D. J. Beal, R. R. Cohen, M. J. Burke, and C. L. McLendon, "Cohesion and Performance in Groups: A Meta-Analytic Clarification of Construct Relations," J. Appl. Psychol., vol. 88, no. 6, pp. 989-1004, 2003.

[25] J. E. Mathieu, M. R. Kukenberger, L. D'Innocenzo, and G. Reilly, "Modeling reciprocal team cohesion-performance relationships, as impacted by shared leadership and members' competence," J. Appl. Psychol., vol. 100, no. 3, pp. 713-734, 2015. 
[26] G. Croy and N. Eva, "Student success in teams: intervention, cohesion and performance," Educ. Train., 2018.

[27] M. A. G. Peeters, C. G. Rutte, H. F. J. M. Van Tuijl, and I. M. M. J. Reymen, "The big five personality traits and individual satisfaction with the team," Small Gr. Res., vol. 37 , no. 2 , pp. 187-211, 2006.

[28] A. Edmondson, "Psychological safety and learning behavior in work teams," Adm. Sci. Q., vol. 44, no. 2, pp. 350-383, Jun. 1999.

[29] A. C. Edmondson and Z. Lei, "Psychological Safety: The History, Renaissance, and Future of an Interpersonal Construct," Annu. Rev. Organ. Psychol. Organ. Behav., vol. 1, no. 1, pp. 23-43, Mar. 2014.

[30] A. C. Edmondson, "Managing the risk of learning: Psychological safety in work teams," in International Handbook of Organizational Teamwork and Cooperative Working, 2008, pp. 255-275.

[31] E. Martínez-Moreno, P. González-Navarro, A. Zornoza, and P. Ripoll, "Relationship, task and process conflicts on team performance: The moderating role of communication media," Int. J. Confl. Manag., vol. 20, no. 3, pp. 251-268, 2009.

[32] K. A. Jehn and E. A. Mannix, "The dynamic nature of conflict: A longitudinal study of intragroup conflict and group performance," Acad. Manag. J., vol. 44, no. 2, pp. 238$251,2001$.

[33] S. A. Carless and C. De Paola, "The measurement of cohesion in work teams," Small Gr. Res., vol. 31, no. 1, pp. 71-88, 2000.

[34] M. L. Loughry and H. L. Tosi, "Performance implications of peer monitoring," Organ. Sci., vol. 19, no. 6, pp. 876-890, 2008.

[35] G. S. Vegt, B. J. M. Emans, and E. Vliert, "Patterns of Interdependence in Work Teams: a Two-Level Investigation of the Relations With Job and Team Satisfaction," Pers. Psychol., vol. 54, no. 1, pp. 51-69, Mar. 2006.

[36] G. J. Greguras, C. Robie, and M. P. Born, "Applying the social relations model to self and peer evaluations," J. Manag. Dev., vol. 20, no. 6, pp. 508-525, 2001.

[37] M. D. Back and D. A. Kenny, "The social relations model: How to understand dyadic processes," Soc. Personal. Psychol. Compass, vol. 4, no. 10, pp. 855-870, 2010.

[38] P. N. Christensen and D. A. Kashy, "Using the social relations model to understand interpersonal perception and behavior.," in APA handbook of research methods in psychology, Vol 3: Data analysis and research publication., Washington, DC: American Psychological Association, 2012, pp. 425-437. 